\title{
Inmunoglobulina intravenosa en el tratamiento de las polineuropatías agudas desmielinizantes
}

\author{
Elba Wu H. ${ }^{1}$; Ana María Alvarez. P. ${ }^{1}$; Carlos Acevedo S. ${ }^{2}$; \\ María Isabel Almarza $B{ }^{3}$; Carmen Larrañaga L. $^{1}$; Jacqueline Malig M. ${ }^{4}$ \\ Treatment of acute demyelinating polineuropathy \\ with intravenous immune globulin
}

\begin{abstract}
The management of acute demyelinating polineuropathy is currantly a controversial issue, particularly in Guillain Barré syndrome. Nowadays the use of intravenous immune globulin (IVIG) in these patients has been proposed, given its beneficial effects upon the immune system, which seems to play a rol in the pathogenesis of these diseases. The clinical cases of three pediatric male patients with severe acute demyelinating polineorupathy, who viere treated with high doses of IVIG are described. Alt three boys showed fast clinical relief and functional muscular activity recovery after only a short period of assisted mechanical ventilation in the two cases in which it was indicated, including ability to walk, which recovered before fifteen days after the begining of treaiment.
\end{abstract}

(Key words: Acute danyelinating polineuropathy, intravenous immune globulin.)

1. Unidad de Infecciosos, Servicio y Departamento de Pediatria y Cirugía lnfantil, Hospital San Juan de Dios, Servicio Salud Metropolita no Occidente, Facultad de Medicina, División Ciencias Médicas Occidente, Universidad de Chille.

2. Servicio de Neuropsiquiatr f́a Infantil, Servicio Salud Metropolitano Occidente.
3. Servicio de Pediatráa, Hospital Parroquial de San Bernardo.

4. Becada. Servicio y Departamento de Pediatría y Cirug á lnfantil, Hospital San Juan de Dios, Facultad de Medicina, División Clencias Médicas Occidente, Universidad de Chile. 
De las polineuropatias agudas desmielinizantes, el síndrome de Guillain Barté es, sin duda, una de las más frecuentes, con una incidencia más o menos uniforme de 0,6 a 1,9 casos por 100000 habitantes, pudiendo afectar a personas de todas las edades y razas ${ }^{1,2}$. Las manifestaciones clínicas de este síndrome son variadas. Su expresión clínica clásica es la parálisis fláccida ascendente y simétrica, pero también puede com. prometer la musculatura respiratoria, los nervios craneanos $y$, con menor frecuencia, la vía sensitiva $y$ el sistema nervioso autónomo ${ }^{i-4}$. El diagnóstico de las polineuropatías agudas đesmielinizantes se basa, además de la presenta. ción clínica, en alteraciones del líquido cefalorraquídeo como disociación albúmino-citológica, que se observa en el sindrome de Guillain Barré $y$, especialmente, en la electromiografía, que muestra signos de desmielinización ${ }^{1-5}$.

La patogenia de estas afecciones no está clara, algunos postulan un mecanismo inmune humoral, ya que se ha encontrado en estos pacientes anticuerpos contra la mielina de nervios periféricos, mientras otros plantean alteraciones en la inmunidad celular ${ }^{1}$. En su tratamiento, además de la terapia de sostén, se ha preconizado el uso de plasmaféresis en las formas severas ${ }^{5}$ $y$, más recientemente, de la inmunoglobulina intravenosa (IGIV) que, además de acelerar la recuperación clínica, disminuiria los costes y riesgos de la plasmaféresis, entre estos últimos los trastomos hemodinámicos y la posibilidad de infección por virus de inmunodeficiencia humana (VIH) $)^{5-10}$.

En este informe se describe la respuesta clínica obtenida en tres niños con polineuropatía desmielinizante aguda, que fueron tratados con inmunoglobulina por vía intravenosa. La preparación empleada es elaborada comercialmente a $\mathrm{pH} 4$, en presencia de sólo trazas de pepsina, lo que deja intacta la molécula de gammaglobulina.

\section{Pacientes}

I. Varón đe 10 años 6 meses de edad, sin antecedentes mórbidos. Ingresó al hospital tras dos días de evolución con mareos, decaimiento, diplopia y dificultad para deglutir; sin cefalea ni fiebre. Al ingresar había paresia de los nervios craneanos VI y $X$ par. El examen citoquímico del líquido cefalorraquídeo y la tomogra. f́a axial computadorizada (TAC) con medio de contraste eran normales. Evolucionó con deterioro progresivo de nervios craneanos (paresia de II], IV, V, VII, X y XI pares y parálisis de VI y IX pares), parálisis de las extremidades y paresia de los músculos respiratorios, por lo que fue necesario conectarle a ventilador mecánico al quinto día de hospitalización. Con el diagnóstico de síndrome de Guillain Barré se le dio tratamiento con IGIV en dosis de $330 \mathrm{mg} \cdot \mathrm{kg} \cdot \mathrm{d}$ ía durante cuatro días. La búsqueda de agentes virales (serología y aislamiento viral en aspirado nasofaringeo, líquido cefalorraquídeo, orina y deposiciones), la de bacterias y la serología para Mycoplasma pneumoniae dieron tesultados negativos. A los tres dias de uso de JGIV se registró detención del deterioro funcional progresivo de extremidades; a los cinco días se retiró el apoyo ventilatorio y era capaz de sentarse sin apoyo, y once días después podía caminar sin apoyo. El compromiso de pares craneanos presenta una regresión más lenta, siendo dado de alta a los 31 días de hospitalización, con leve com. promiso parético de VI y $X$ par craneano. El alta se prolonga hasta 31 días por motivos socioeconómicos.

2. Varón previamente sano, edad 12 años 10 meses, con historia reciente de diarrea autolimitada. Cuatro días antes de ingresar notó falta de fuerzas en las extremidades inferiores, que luego ascendió a las superiores; un dia después no podía caminar, agregándose dificultad para hablar y deglutir. No tenía fiebre ni signos de hiper tensión intracranea na. En el examen inicial habí tetraparesia fláccida, hiporreflexia y deterioro progresivo de los nervios craneanos (III, VI, VII, IX, X, XI y XII pares); disociación albúmino-citológica en el líquido cefalorraquideo y ausencia de signos de hemorragia o proceso expansivo intracraneanos en la tomografía axial. Por estas manifestaciones $y$ li aparición de compromiso de musculatura respiratoria se planteó el diag. nóstico de síndrome de Guillain Barré, indicándose ventilación mecánica e IGIV en dosis de $400 \mathrm{mg} \cdot \mathrm{kg} \cdot \mathrm{d}$ ía durante cuatro días sucesivos. Los estudios para virus, bacterias y. . pneumonize dieron resultados negativos. En un nuevo examen de líquido cefalorraquídeo persistía la disocisción albúmino-citológica y la electromiografia, realizada a los 15 días de hospitalización, mostraba moderado compromiso neurogénico sensitivomotor en regresión, predominantemente de extremidades inferiores, con velocidad de conducción motora disminuida. La evolución fue satisfactoria y rápida, pues mejoró notablemente la fuesza de extremidades a los dos días de tratamiento con IGIV, lo que, junto con la recuperación de la capacidad mecánica respiratoria, permitiezon retiratlo del respirador a los cinco días de iniciada la asistencia ventilatoria. El deterioro de los pares craneanos se recuperó más lentamente, especialmente el de VII par, siendo capaz de alimentarse por la boca al sexto día y caminar sin ayuda al octavo. Fue dado de alta 12 días después de ingresar.

3. Varón de 11 años 3 meses de edad, atleta. Sus molestias iniciales fueron debilidad, alteración de la sensibilidad y dolor en extremidades inferiores, seguidos de limitación funcional progresiva, incapacidad para correr y subir escaleras, se cansaba al carninar y notaba pérdjda de fuerzas en extrernidades superiores. Al examinarle había tetraparesia simétrica, con mayor compromiso crural, arreflexia, disestesias en extremidades inferiores. hipotonía global, sin alteraciones de los pares cranearos. A las tres semanas de evolución se describia, en la electromiografía, evidencia de polineuropatía sensitivo-motora de las 4 extremidades, que predominaba en las inferiores, con signos de desmieliniza- 
ción severa. El examen citoquímico y el análisis de bandas oligocionales en el liquido cefalorraquídeo, con respecto al suero, fueron notmales. No se realizaron estudios microbiológicos. El paciente evolucionó sin fiebre, con aumento de la tetraparesia y sin afección de los pares craneanos. A las 3 semanas de evolución presentó dolor abdominal intenso, sin poderse precisar su origen, por lo que se hospitalizó en una clínica privada, indicándosele corticoesteroides durante cinco días, sin resultados positivos, al cabo de los cuales se le dio IGIV en dosis de $400 \mathrm{mg} \cdot \mathrm{kg}$ - día por cuatro días. En la semana siguiente, con IGIV se observó disminución y luego desaparición de los dolores abdominal y de las extremidades inferiores. La marcha se recuperó a los 15 días de tratamiento y sólo por poco tiempo persistió leve debilidad muscular símétrica. A los dos meses de realizado el tratamiento con IGIV fue capaz de reiniciar su actividad deportiva normal.

\section{Comentario}

El manejo de los pacientes con polineuropatía desmielinizante aguda es tema de controversia, ya que hasta ahora los beneficios de algunos tratamientos como corticoides y plasmaféresis no han sido del todo probados ${ }^{9}$. La terapia de sostén es, sin lugar a dudas, uno de los pilares del tratamiento. Hasta $30 \%$ de los casos que son diagnosticados como síndrome de Guillain Barré presentan compromiso respiratorio y pueden requerir de ventilación mecánica por largo tiempo, con los consiguientes riesgos vitales y postergación de la recuperación motora por semanas. La hospitalización prolongada, la utilización de unidades de tratamiento intensivo y el empleo, preconizado hasta hace poco tiempo, de plasmaféresis, implican no pocos riesgos y alto coste ${ }^{1-5}$. Más recientemente se ha propuesto el uso de IGIV en estos casos, cuya patogenia seria inmunitaria ${ }^{5-13}$. Los posibles mecanismos de acción de la IGIV serían la etiminación de complejos inmunes circulantes, provisión de anticuerpos antiidiotipos, disminución selectiva de la concentración de anticuerpos patogénicos y bloqueo de los receptores $\mathrm{Fc}$ de linfocitos y macrófagos ${ }^{7}$. También se ha postulado que actuaría impidiendo el daño tisular mediado por complemento o linfocitos citotóxicos ${ }^{11}$. El análisis preliminar de un gran estudio randomizado, multicéntrico, de EE.UU,, en que se compara el uso de IGIV y plasmaféresis en pacientes con sindrome de Guillain-Barré, muestra mejor recuperación funcional de los pacientes que recibieron IGIV. No todas las preparaciones de IGIV producirían estos berieficios, ya que algunas son elaboradas con técnicas que, como el uso de plasmina u otros métodos, dañan la estructura y funcionalidad de los anticuerpos. Para que las IGIV tengan una acción optima, se requiere que estén constjtuidas en mayor proporción por inmunoglobulinas de forma monomérica, la distribución de clases y subclases sea lo más semejante posible al plasma y la fracción Fc esté indemne.

En los pacientes que se comentan, tratados con IGIV en altas dosis por cuatro días sucesivos, se observó detención de la evolución de la enfermedad, rápida disminución de los signos clínicos de la enfermedad y mejoría clínica, o que sugiere que este tratamiento representa un avance, pues disminuye la duración de la enfermedad, la posibilidad de complicaciones, la letalidad y los costes.

\section{Resumen}

El manejo de las polineuropatias agudas desmielinizantes está aún en discusión, especialmente el sindrome de Guillain-Barré. El empleo de inmunoglobulina con molécula intacta por via endovenosa y los efectos benéficos observados en coincidencia con su uso, se ilustran en tres pacientes varones de 10 años 6 meses, 11 af̆os 3 meses y 12 años 10 meses, respectivamente, todos ellos severamente afectados -los dos primeros con compromiso de los músculos respiratorios-, que fueron tratados con dosis altas, de 300 a $400 \mathrm{mg} \cdot \mathrm{kg}$. dia durante cuatro días, con rápida recuperación clínica, manifestada por apoyo ventilatorio de corta duración en los casos que lo requirieron y reinicio de la marcha espontánea en menos de 15 dias después del tratamiento.

(Palabras claves: Polineuropatía desmielinizante aguda, sindrome de Guillain-Barré, inmunoglobulina intravenosa.)

\section{Referencias}

1. Englond JD: Guillain-Barré Syndrome. Annu Rev Med 1990;41:1-6.

2. Rantala $H$, Uhari $N$, Niemelä $M$ : Occurrence, clinical manifestation, and prognosis of GuillainBarré Syndrome. Arch Dis Child 1991; 66: 706709.

3. Mastcci EF. Kurtzke JF: Diagnostic criteria for the Guillain-Barre Syndrome. An analysis of 50 cases. J Neurol Sci 1971;13:483-501.

4. Asbury AK, Cornblatd DR: Assessement of current diagnostic criteriz for Guilhain-Barré Syndrome. Ann Neurol 1989; 7 (suppl): 21-27. 
5. The Guillain-Barre Syndrome Study Group, Plasmapheresis and acute Gujllain-Barré Syndrome. Neurology 1985; 35:1096-1104.

6. Shahar $E$, Murphy $G$, Roifman Ch: Benefit of intravenously administered immune serum ghobulin in patients with Guillain-Barré Syndrome. J Pediati 1990;116: 141-144.

7. Siehm $E R$ : New uses for intravenous immune globulin. N Engl J Med 1991 ; 325: 123-125.

8. Cook JD, Delgado MR, Soutter-Glass D: Treatment of childhood autoimmune polyneuropathy: III Gammaglobulin. Netrology 1987; 37 (suppl 1): 253.

9. Kleyweg $R P$, Van der Meche $F G A$, Meulstee $J$ : Treatment of Guillain-Barré Syndrome with high dose gammaglobulin. Neurology 1988; $38: 1639$. 1641 .
10. Matro $G$ : Un cas de syndrome de Guillain-Barré traité par fortes doses d'immunoglobulines par voie intraveinuse. Rev Neurol (Paris). J989; 145: $731-732$.

11. NH Consensus Conference. Intravenous inimuneglobulin. Prevention and treatment of disease. JAMA $1990: 264: 3189-3193$.

12. Von der Meche FGA, Schmitz PIM and The Ductch Guillain-Bare Study Group: A randomized trial comparing intravenous immune globulin and plasma exchange in Guillain-Barré Syndrome. Xy Engl J Med 1992: 326:1123-1129.

13. Ropper $A$ : The Guillajn-Barré syndrome, N Engl J Med 1992:326:1130-1136. 